\title{
Hsa_circRNA_0054633 is highly expressed in gestational diabetes mellitus and closely related to glycosylation index
}

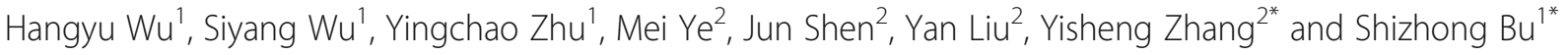

\begin{abstract}
Background: Circular RNA (circRNA) is involved in the pathological processes of various diseases. CircRNA is more stable than linear RNAs and is expressed in high levels in tissues, making it a better biomarker candidate than linear RNAs. In this study, we aimed to identify potential circRNA biomarkers of gestational diabetes mellitus (GDM).

Methods: A retrospective case-control study was conducted using data and samples from women treated at a hospital in China between July 10, 2017, and February 15, 2018. We collected serum samples from 40 healthy pregnant women (controls) and 40 women with GDM (cases) during the second trimester as well as 65 controls and 65 cases during the third trimester of pregnancy. Placenta tissues and neonatal cord blood were each from another 20 cases and 20 controls. We selected six circRNAs (hsa_circRNA_0054633, hsa_circRNA_103410, hsa_circRNA_063981, hsa_circRNA_102682, hsa_ circRNA_0018508, and hsa_circRNA_406918) as candidate biomarkers and used quantitative reverse transcriptase polymerase chain reaction (qRT-PCR) to measure their concentrations in the serum and placental tissues. The Pearson correlation test was used to assess the correlation between various circRNAs and between circRNA and clinical variables. The area under the receiver operating characteristic (ROC) curve was used to assess the diagnostic value of circRNAs for GDM at each stage.
\end{abstract}

Results: Hsa_circRNA_0054633 was highly expressed in the blood during the second and third trimesters; its expression was also high in the placenta but low in the cord blood $(P<0.05)$. Hsa_cirRNA_0054633 was highly correlated with GHBA1 and GHBA1c levels in maternal blood samples at various stages of the GDM group (including placental tissue and umbilical cord blood) $(P<0.05)$. Hsa_circRNA_063981, hsa_circRNA_102682, and hsa_circRNA_103410 were also differentially expressed between the case and control groups at different stages $(P<0.05)$. There was a strong correlation between hsa_circRNA_0054633 and hsa_circRNA_103410 levels in third-trimester maternal blood $(P=0.000, r=0.554)$ and in neonatal umbilical cord blood $(P=0.000, r=0.866)$. Hsa_circRNA_0054633 showed a significant diagnostic value in the second and third trimesters of pregnancy, placenta, and cord blood (AUC $=0.793,0.664,0.747$, and 0.783 , respectively, $P<0.001)$.

Conclusion: This study suggests that hsa_cirRNA_0054633 is abnormally expressed in GDM patients and may play a potential role in the development of GDM. The possibility of using circRNAs for the diagnosis of GDM requires additional investigation in future studies.

Keywords: Circular RNA, Hsa_circRNA_0054633, Gestational diabetes mellitus (GDM), Biomarker

\footnotetext{
*Correspondence: nbzhangys@163.com; bushizhong@nbu.edu.cn

${ }^{2}$ Department of Gynaecology and Obstetrics, Ningbo University Medical

Center Lihuili Eastern Hospital, Taipei Medical University, 1111 Jiangnan Road,

Ningbo 315048, Zhejiang, China

'Diabetes Research Center, Medical School, Ningbo University, 818 Fenghua

Road, Ningbo 315211, Zhejiang, China
}

(c) The Author(s). 2019 Open Access This article is distributed under the terms of the Creative Commons Attribution 4.0 International License (http://creativecommons.org/licenses/by/4.0/), which permits unrestricted use, distribution, and reproduction in any medium, provided you give appropriate credit to the original author(s) and the source, provide a link to the Creative Commons license, and indicate if changes were made. The Creative Commons Public Domain Dedication waiver (http://creativecommons.org/publicdomain/zero/1.0/) applies to the data made available in this article, unless otherwise stated. 


\section{Introduction}

Gestational diabetes mellitus (GDM) refers to the condition of having normal glucose metabolism before pregnancy but impaired glucose tolerance and elevated fasting glucose concentrations during pregnancy [1]. The prevalence of GDM varies from country to country and even from region to region [2]. The latest epidemiological studies show that the prevalence of GDM in the USA is 9\% [2], while the incidence of GDM in Asian countries is $3.0-21.2 \%$ [3]. With the increase in the rate of obesity and the increase in maternal age, the incidence of gestational diabetes is increasing [4]. Women who develop hyperglycemia during pregnancy often have increased risks of adverse pregnancy outcomes. In 2013, the International Diabetes Federation (IDF) reported that an estimated 21.4 million live births were from women with GDM [5], and these newborns were prone to macrosomia, shoulder dystocia, and neonatal hypoglycemia [5, 6]. At present, diagnosis of GDM relies primarily on the diagnostic criteria given by the American Diabetes Association (ADA) and the International Association of Diabetes and Pregnancy Study Group (IADPSG) [7]. A standard test is performed during 24 to 28 weeks of gestation, sometimes delayed to 32 weeks. Testing at this stage can often delay the diagnosis of GDM, causing serious adverse consequences for the mother and child. In addition, some biomarker detection methods, such as mid-pregnancy plasma protein profile analysis, hair metabolomics (concentration of adipic acid), and capillary blood glucose, have low diagnostic sensitivity to GDM [8-10]. Therefore, an early stage, highly sensitive biomarker of GDM is needed. Some researchers have sought to find new indicators of GDM through associations between genetic variants and GDM $[11,12]$, but delays the diagnosis of the disease, causing adverse consequences.

Circular RNA (circRNA) is a recently discovered endogenous non-coding RNA. Studies have found that circRNAs play important roles in the regulation of gene expression, which suggests that circRNAs have great potential in clinical diagnosis and treatment. In a circRNA, the 3' and $5^{\prime}$ ends are linked to form a complete circular structure, so circRNAs are resistant to the degradation by RNA exonucleases and therefore have higher biological stability than linear RNAs. It is widely found in a variety of organisms, and a large number of circRNAs are found in humans, mice, nematodes, and plants [13]. CircRNAs play important roles in various diseases including atherosclerosis, diabetes, and cancer [14-17]. The high biological stability of circRNA is ideal for its use as a biomarker for disease. It has been reported that circRNA is involved in the regulation of insulin secretion and pathogenesis of diabetes. CircRNA-CDR1 is a natural antisense transcript of CDR1 and has been found to regulate insulin secretion and $\beta$ cell renewal [18]. Yan et al. found that circRNAs were abnormally expressed in placental tissues of GDM patients and that 227 circRNAs were significantly upregulated and 255 circRNAs were significantly downregulated [16]. Although some reports have suggested that circRNAs may be involved in GDM, whether these circRNAs are potential biomarkers is not clear. Diseases often alter the mother's physiological condition, so placental epigenetics such as circRNA expression levels may be affected by the adverse environment of GDM patients and may reflect their diet and metabolic status [19]. In addition, the origin of most GDM-related adverse pregnancy outcomes can be traced back to the placenta. Studies have found that GDM exhibits immature placental villi or changes in villus branch morphology, which ultimately leads to changes in placental morphology and function, resulting in limited intrauterine growth and increased risk of preterm birth [20]. Additionally, epigenetic changes in the peripheral blood of GDM patients might be potential biomarkers for GDM diagnosis and disease detection.

Therefore, we studied the peripheral blood of pregnant women during the second and third trimesters as well as the placenta and umbilical cord blood after childbirth. Real-time quantitative PCR was used to determine the levels of six circRNAs in the serum and placental tissues to lay a foundation for the discovery of potential early biomarkers for GDM.

\section{Results \\ Participant characteristics}

Table 1 shows the characteristics of the women and newborns in the second and third trimesters. There were no significant differences in the age, educational level, pre-pregnancy BMI, gestational age, or delivery methods between cases and controls ( $P>0.05$ for all). Table 1 also shows that there was no significant difference in the birth weight of the baby, neonatal apgar score, or the incidence of fetal distress between the control group and the GDM group $(P>0.05)$. However, the BMI of women with GDM was significantly higher than that of the controls $(P<0.05$, Table 1$)$. In addition, the incidence of neonatal hypoglycemia in the GDM group was significantly higher than that in the control group $(P<0.05)$.

\section{Clinical chemical analyses}

We tested a comprehensive metabolic panel, anemia index, and glycosylated hemoglobin level in the maternal serum samples (Table 2). Glycated hemoglobin levels (GHBA and GHBA1c) were higher in the GDM group than in the control group $(P<0.05)$ in both cohorts. Total cholesterol concentrations in the controls were significantly lower than those in GDM patients $(P<0.05)$. In the third-trimester cohort, the serum concentration of HDL cholesterol in the controls was significantly higher than 
Table 1 The clinical characteristics of the study population (second and third trimester mothers and neonates of the third trimester mothers)

\begin{tabular}{|c|c|c|c|}
\hline Characteristic & Healthy control group $(n=40)$ & Gestational diabetes mellitus group $(n=40)$ & $P$ value \\
\hline \multicolumn{4}{|l|}{ Second trimester } \\
\hline Age, year & $29.88 \pm 3.77$ & $31.80 \pm 3.99 \mathrm{~s}$ & 0.427 \\
\hline High school education or lower, \% (n) & $28(70)$ & $26(65)$ & 0.633 \\
\hline Gestational age, weeks & $24.20 \pm 2.34$ & $23.97 \pm 2.45$ & 0.900 \\
\hline Height, cm & $160.58 \pm 3.89$ & $160.92 \pm 5.40$ & 0.792 \\
\hline Mid-pregnancy weight, kg & $59.92 \pm 11.69$ & $64.96 \pm 7.69$ & 0.156 \\
\hline History of abortion, \% (n) & $13(33)$ & $14(35)$ & 0.813 \\
\hline Pre-pregnancy BMl, kg/m² & $22.14 \pm 2.26$ & $23.30 \pm 2.51$ & 0.075 \\
\hline Mid-pregnancy BMI, kg/m² & $23.13 \pm 3.18$ & $25.14 \pm 2.50$ & $0.014^{*}$ \\
\hline Third trimester & Healthy control group $(n=65)$ & Gestational diabetes mellitus group $(n=65)$ & $P$ value \\
\hline Age, year & $29.06 \pm 3.66$ & $30.04 \pm 3.67$ & 0.244 \\
\hline High school education or lower, \% (n) & $40(62)$ & $47(72)$ & 0.192 \\
\hline Gestational age, weeks & $38.54 \pm 1.98$ & $38.09 \pm 2.68$ & 0.276 \\
\hline Height, cm & $160.63 \pm 4.84$ & $160.09 \pm 4.72$ & 0.255 \\
\hline Late-pregnancy weight, kg & $67.37 \pm 8.27$ & $69.47 \pm 7.73$ & 0.141 \\
\hline Pre-pregnancy BMl, kg/m² & $21.25 \pm 3.10$ & $21.50 \pm 2.54$ & 0.274 \\
\hline Late-pregnancy BMI, kg/m² & $26.08 \pm 2.84$ & $27.22 \pm 2.74$ & $0.022^{*}$ \\
\hline Gravidity & $2.22 \pm 1.45$ & $2.31 \pm 1.52$ & 0.869 \\
\hline Parity & $0.48 \pm 0.59$ & $0.40 \pm 0.52$ & 0.512 \\
\hline \multicolumn{4}{|l|}{ Mode of delivery, \% ( $n$ ) } \\
\hline Cesarean & $26(40)$ & $30(46)$ & 0.479 \\
\hline Vaginal & $39(60)$ & $35(54)$ & \\
\hline History of abortion \% (n) & $8(12)$ & $9(14)$ & 0.795 \\
\hline \multicolumn{4}{|l|}{ Neonates } \\
\hline Neonatal birth weight, kg & $3.31 \pm 0.44$ & $3.38 \pm 0.41$ & 0.301 \\
\hline \multicolumn{4}{|l|}{ Apgar score } \\
\hline $1 \mathrm{~min}$ & $8.95 \pm 0.29$ & $8.82 \pm 0.72$ & 0.329 \\
\hline $10 \mathrm{~min}$ & $9.98 \pm 0.13$ & $9.95 \pm 0.22$ & 0.311 \\
\hline Macrosomia and premature infants, \% (n) & $5(7.7)$ & $8(12.3)$ & 0.380 \\
\hline Neonatal hypoglycemia, \% (n) & $1(1.5)$ & $8(12.3)$ & $0.016^{*}$ \\
\hline Fetal distress, \% (n) & $1(1.5)$ & $4(6.2)$ & 0.171 \\
\hline
\end{tabular}

Abbreviations: BMI body mass index (calculated as weight in kilograms divided by the square of height in meters)

Values are given as mean \pm SD or number (percentage), unless otherwise indicated

${ }^{*} p$ value from $t$ test or chi-squared test comparing means or proportions between GDM cases and controls in the current study. $P<0.05$ was considered statistically significant

that in the GDM group, while the APOB concentration was significantly lower than that in GDM patients $(P<0.05)$. In addition, there was no significant difference in hemoglobin, electrolyte level, anemia index, ALT, or AST between the cases and controls $(P>0.05)$.

Hsa_circRNA_0054633 was highly expressed during the second trimester and was associated with changes in glycated hemoglobin

To test the six candidate circRNAs, qRT-PCR was performed for the second-trimester cohort (Fig. 1). The level of
hsa_circRNA_0054633 in GDM patients was significantly higher than in the controls $(P<0.001$, Additional file 1: Table S2). However, there were no significant differences in the levels of other circRNAs between the two groups. Next, we analyzed the correlation between the hsa_circRNA_0054633 level and blood biochemical markers in GDM maternal serum. The level of hsa_circRNA_0054633 was significantly correlated with 2-h glucose, GHBA1, and GHBA1c, and the correlation coefficients were $0.532,0.318$, and 0.331 , respectively $(P<0.05$, Additional file 1: Table S3). Hsa_circRNA_0018508 was 
Table 2 Variables associated with gestational diabetes mellitus

\begin{tabular}{|c|c|c|c|}
\hline Variable & Healthy control group $(n=40)$ & Gestational diabetes mellitus group $(n=40)$ & $P$ value \\
\hline \multicolumn{4}{|l|}{ Mid-pregnancy characteristics (T1) } \\
\hline \multicolumn{4}{|l|}{ OGTT } \\
\hline Fasting glucose, $\mathrm{mmol} / \mathrm{L}$ & $4.01 \pm 0.31$ & $4.81 \pm 0.58$ & $0.000^{*}$ \\
\hline 1-h glucose, $\mathrm{mmol} / \mathrm{L}$ & $6.82 \pm 1.27$ & $9.83 \pm 1.37$ & $0.000^{*}$ \\
\hline 2-h glucose, $\mathrm{mmol} / \mathrm{L}$ & $5.95 \pm 0.95$ & $8.54 \pm 0.85$ & $0.000^{*}$ \\
\hline \multicolumn{4}{|l|}{ Comprehensive metabolic panel } \\
\hline $\mathrm{ALT}, \mathrm{U} / \mathrm{L}$ & $16.85 \pm 7.54$ & $14.96 \pm 12.30$ & 0.064 \\
\hline AST, U/L & $20.07 \pm 4.56$ & $18.16 \pm 7.62$ & 0.083 \\
\hline TBA, umol/l & $2.39 \pm 1.31$ & $2.90 \pm 2.01$ & 0.306 \\
\hline Hemoglobin, g/L & $111.69 \pm 14.97$ & $115.10 \pm 9.60$ & 0.306 \\
\hline Triglycerides, $\mathrm{mmol} / \mathrm{L}$ & $3.07 \pm 1.14$ & $3.66 \pm 1.61$ & $0.029^{*}$ \\
\hline Total cholesterol, mmol/L & $5.70 \pm 0.83$ & $5.72 \pm 0.90$ & 0.798 \\
\hline $\mathrm{HDL}-\mathrm{C}, \mathrm{mmol} / \mathrm{L}$ & $1.91 \pm 0.22$ & $1.83 \pm 0.32$ & 0.721 \\
\hline $\mathrm{LDL}-\mathrm{C}, \mathrm{mmol} / \mathrm{L}$ & $3.43 \pm 0.48$ & $3.23 \pm 0.63$ & 0.721 \\
\hline GHBA1, \% & $6.41 \pm 0.44$ & $7.10 \pm 0.90$ & $0.003^{*}$ \\
\hline GHBA1C, \% & $4.71 \pm 0.24$ & $5.23 \pm 0.56$ & $0.001^{*}$ \\
\hline \multicolumn{4}{|l|}{ Three tests for anemia } \\
\hline Ferritin, umol// & $21.63 \pm 26.56$ & $21.82 \pm 14.73$ & 0.55 \\
\hline Folic acid, nmol/L & $26.57 \pm 12.36$ & $29.20 \pm 16.32$ & 0.684 \\
\hline Vitamin B12, pmol/L & $265.39 \pm 107.12$ & $245.82 \pm 55.51$ & 0.987 \\
\hline Variable & Healthy control group $(n=65)$ & Gestational diabetes mellitus group $(n=65)$ & $P$ value \\
\hline \multicolumn{4}{|l|}{ Late-pregnancy features (T2) } \\
\hline GHBA1, \% & - & $7.25 \pm 0.99$ & - \\
\hline GHBA1C, \% & - & $5.45 \pm 0.61$ & - \\
\hline Hemoglobin, g/L & $125.83 \pm 10.8$ & $125.09 \pm 13.68$ & 0.733 \\
\hline \multicolumn{4}{|l|}{ Comprehensive metabolic panel } \\
\hline $\mathrm{ALT}, \mathrm{U} / \mathrm{L}$ & $13.65 \pm 9.23$ & $13.69 \pm 5.95$ & 0.479 \\
\hline AST, U/L & $20.29 \pm 5.64$ & $20.37 \pm 5.87$ & 0.887 \\
\hline Glucose, mmol/l & $4.19 \pm 0.61$ & $4.63 \pm 1.14$ & $0.007^{*}$ \\
\hline Triglycerides, mmol/L & $2.76 \pm 0.98$ & $3.61 \pm 1.59$ & $0.000^{*}$ \\
\hline Total cholesterol, mmol/L & $5.80 \pm 1.17$ & $5.74 \pm 1.09$ & 0.793 \\
\hline $\mathrm{HDL}-\mathrm{C}, \mathrm{mmol} / \mathrm{L}$ & $1.95 \pm 0.41$ & $1.78 \pm 0.34$ & $0.009^{*}$ \\
\hline $\mathrm{LDL}-\mathrm{C}, \mathrm{mmol} / \mathrm{L}$ & $3.35 \pm 0.84$ & $3.28 \pm 0.87$ & 0.596 \\
\hline APOA1, g/L & $2.26 \pm 0.39$ & $2.16 \pm 0.29$ & 0.188 \\
\hline$A P O E, g / L$ & $1.26 \pm 0.29$ & $1.26 \pm 0.28$ & 0.993 \\
\hline $\mathrm{APOB}, \mathrm{mg} / \mathrm{dL}$ & $8.31 \pm 1.46$ & $9.07 \pm 2.03$ & $0.018^{*}$ \\
\hline TBA, umol/l & $3.37 \pm 2.46$ & $3.58 \pm 2.37$ & 0.241 \\
\hline $\mathrm{K}, \mathrm{mmol} / \mathrm{l}$ & $3.93 \pm 0.29$ & $3.94 \pm 0.28$ & 0.576 \\
\hline $\mathrm{NA}, \mathrm{mmol} / \mathrm{l}$ & $138.68 \pm 1.51$ & $138.48 \pm 1.59$ & 0.464 \\
\hline $\mathrm{CA}, \mathrm{mmol} / \mathrm{l}$ & $2.18 \pm 0.11$ & $2.20 \pm 0.11$ & 0.686 \\
\hline $\mathrm{P}, \mathrm{mmol} / \mathrm{l}$ & $1.22 \pm 0.21$ & $1.23 \pm 0.15$ & 0.422 \\
\hline $\mathrm{Mg}, \mathrm{mmol} / \mathrm{l}$ & $0.71 \pm 0.09$ & $0.71 \pm 0.14$ & 0.880 \\
\hline
\end{tabular}


Table 2 Variables associated with gestational diabetes mellitus (Continued)

\begin{tabular}{|c|c|c|c|}
\hline \multicolumn{4}{|l|}{ Three tests for anemia } \\
\hline Ferritin, umol/l & $28.48 \pm 18.91$ & $28.19 \pm 21.09$ & 0.108 \\
\hline Folic acid, nmol/L & $28.22 \pm 11.59$ & $31.52 \pm 11.64$ & 0.503 \\
\hline Vitamin B12, pmol/L & $232.05 \pm 92.71$ & $242.25 \pm 80.16$ & 0.733 \\
\hline
\end{tabular}

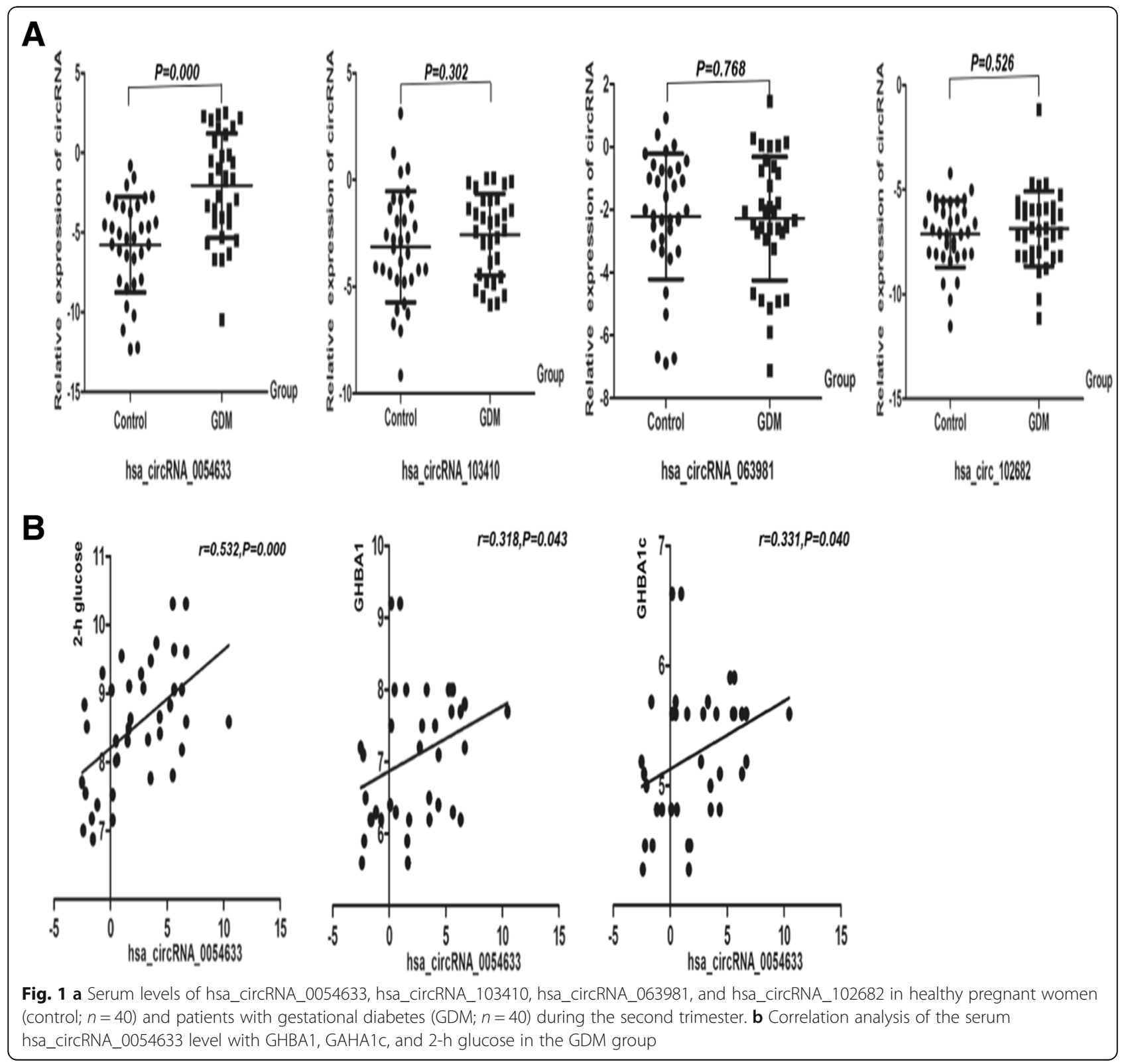


expressed during the second trimester, and its level in the serum was correlated with that of hsa_circRNA_0054633 $(P<0.05)$, but it was not expressed in the third trimester (Additional file 1: Figure S1). The specific cause of this is unknown.

Hsa_circRNA_0054633 was also highly expressed in the third trimester in the GDM group and was correlated with hsa_circRNA_103410

By qRT-PCR, we also found that the level of hsa_circRNA_0054633 in GDM patients was significantly higher than that in the controls in the third-trimester cohort $(P=0.002$, Fig. 2$)$. There was a significant correlation between the level of hsa_circRNA_0054633 and the level of hsa_circRNA_103410 in the serum of GDM patients $(P=0.000, r=0.554)$. However, the level of hsa_circRNA_103410 was not significantly different between the cases and controls during the third trimester of pregnancy. In addition, the levels of hsa_circRNA_063981 and hsa_circRNA_102682 in healthy subjects were significantly higher than those in the GDM group $(P<0.05)$.

Hsa_circRNA_0054633 level was low in the umbilical cord blood of newborns in the GDM study group and was correlated with serum hsa_circRNA_103410 level and maternal glycosylated hemoglobin

As shown in Fig. 3, the level of hsa_circRNA_0054633 in cord blood was significantly higher in the controls than in the GDM group $(P<0.05)$, while the level of hsa_circRNA_063981 was lower than that in the GDM group ( $P$ $<0.05)$. Next, we analyzed the correlation between the levels of these circRNAs and between the circRNA level and laboratory biochemical indicators. The level of hsa_circRNA_0054633 was highly correlated with maternal GHBA1 and GHBA1c, and the correlation coefficients were 0.885 and 0.921 , respectively $(P<0.001$, Additional file 1 :

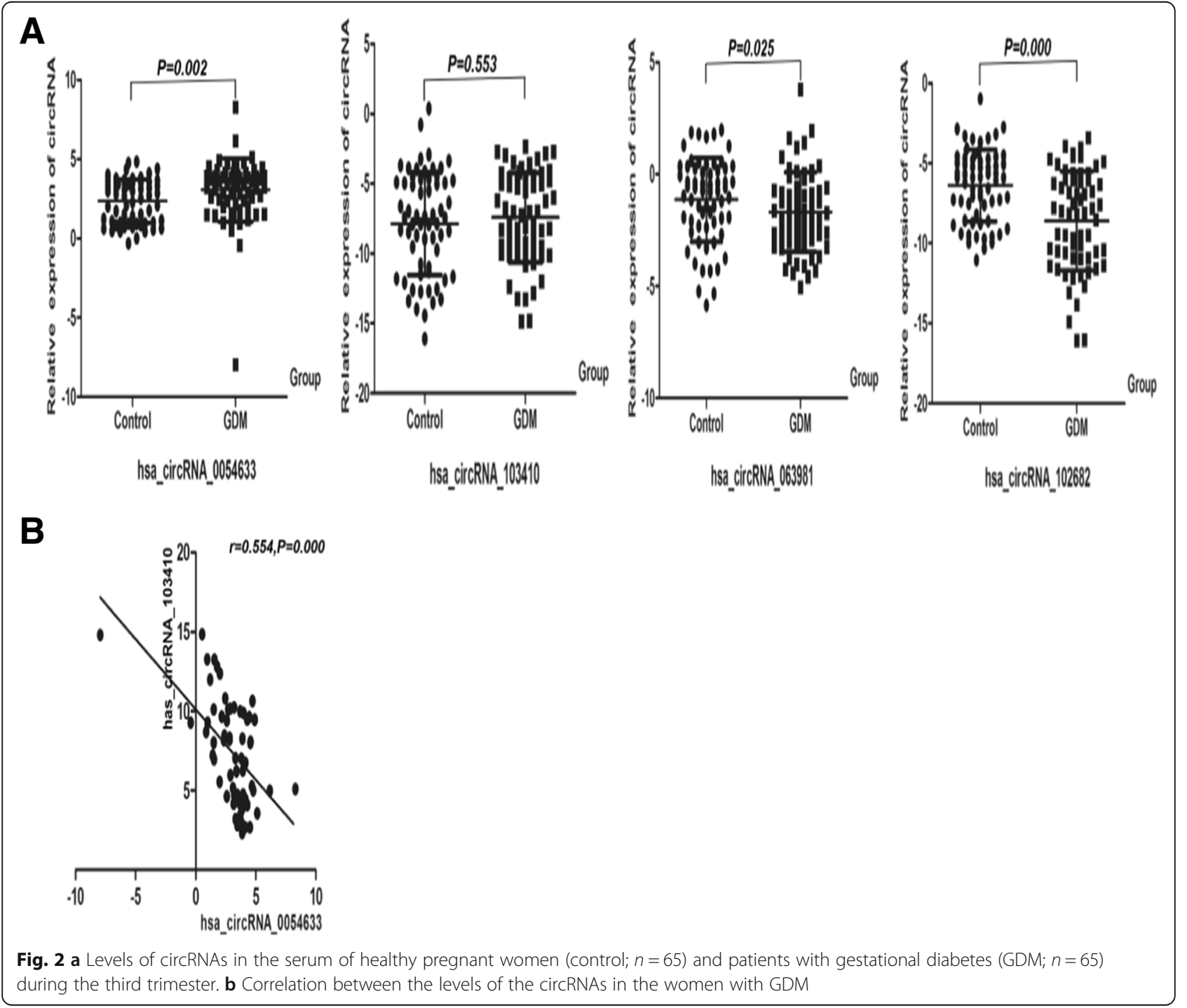




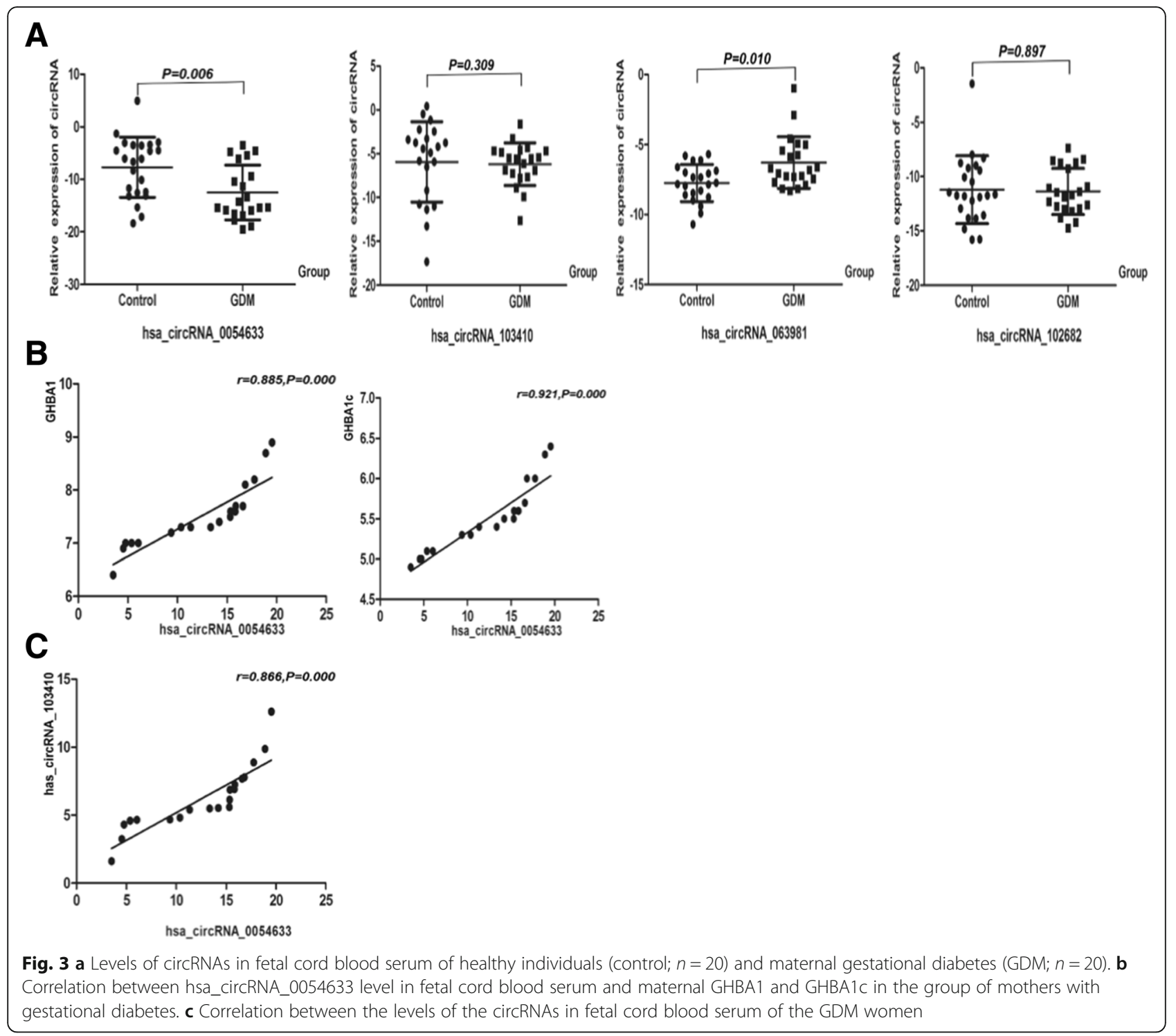

Table S3). The level of hsa_circRNA_0054633 was correlated with that of hsa_circRNA_103410 $(P=0.000, r=0.866)$ in the neonatal cord blood of the GDM group. However, there were no significant correlations between other circRNAs and clinical biochemical indicators.

Hsa_circRNA_0054633 was highly expressed in placental tissues of the GDM study group and related to the development of GDM

The expression of hsa_circRNA_0054633 in the placental tissue of the GDM group was significantly higher than that of the healthy group. In addition, hsa_circRNA_103410 expression was higher in the GDM placental tissue than in the control placental tissue $(P<0.05$, Fig. 4$)$. Correlation analysis showed that the expression of hsa_circRNA_0054633 in the placenta of the case group was correlated with the levels of GHBA1 and
GHBA1c in maternal blood $(P<0.05, r=0.446$ and $r=0.483$, respectively). To determine if there is a correlation between circRNAs, we analyzed the correlation between the expression of different circRNAs and found that hsa_circRNA_0054633 and hsa_circRNA_102682 levels $(P=0.024, r=0.470)$, as well as hsa_circRNA_103410 and hsa_circRNA_063981 levels, were correlated $(P=0.010, r=0.521)$.

ROC curve analysis of differentially expressed circRNAs

The area under the ROC curve was used to determine the diagnostic value of circRNAs for GDM and neonatal complications (Fig. 5). The area under the curve (AUC) of hsa_circRNA_0054633 during the second trimester was 0.793 (0.685-0.901, $P=0.000$ ); its best sensitivity and specificity were $57.6 \%$ and $90.9 \%$, respectively. In the third trimester, the AUC of hsa_circRNA_0054633, hsa_circRNA_063981, and hsa_circRNA_102682 was $0.664 \quad(0.569-0.758, \quad P=0.002)$, 

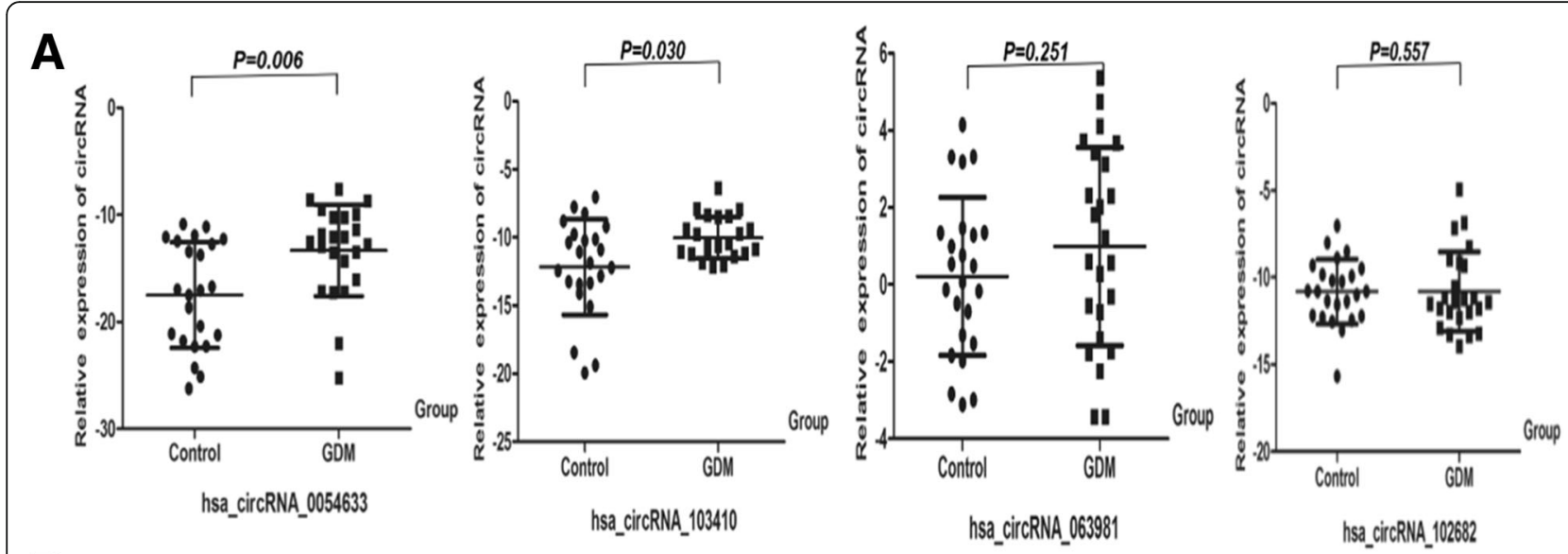

B
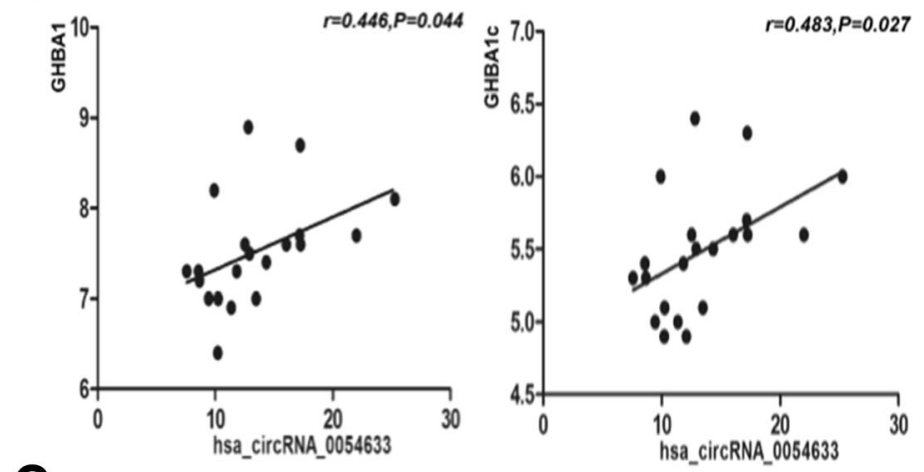

C
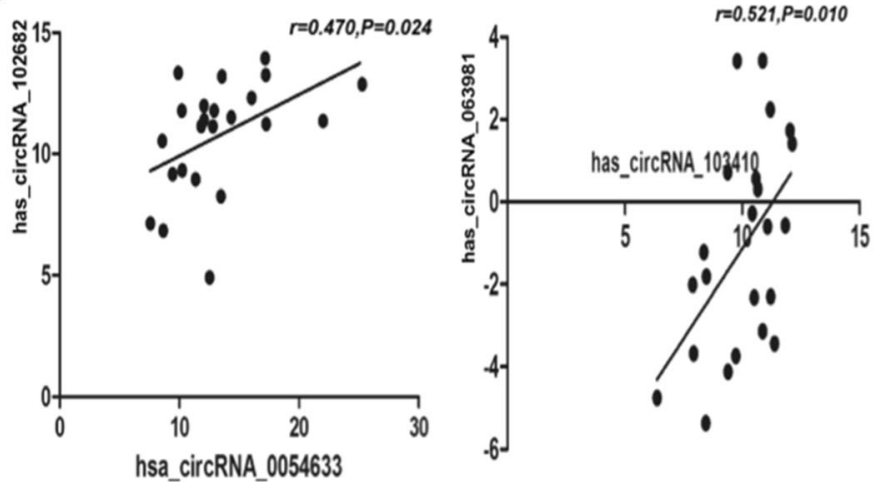

Fig. 4 a Levels of circRNAs in placenta tissues of healthy individuals (controls; $n=20)$ and gestational diabetes (GDM; $n=20)$. b Correlation between the hsa_circRNA_0054633 level in the placenta and maternal GHBA1 and GHBA1c in the GDM group. c Correlation of between the levels of the circRNAs in placental tissues of the GDM women

$0.615(0.517-0.714, P=0.025)$, and $0.706(0.617-0.795$, $P=0.000)$, respectively; the sensitivity and specificity were $39.1 \%$ and $88.7 \%, 54.0 \%$ and $71.9 \%$, and $96.9 \%$ and $37.5 \%$, respectively. In umbilical cord blood, the AUC of hsa_circRNA_103410 and hsa_circRNA_0054633 was $0.729(0.581-0.878, P=0.010)$ and $0.747(0.600-0.894$, $P=0.747$ ), respectively. Furthermore, the AUC of hsa_circRNA_0054633 in the placental tissue was 0.735 (0.591-0.880, $P=0.006)$, with a sensitivity and specificity of $78.3 \%$ and $60.9 \%$, respectively. The AUC of hsa_circRNA_063981 was $0.686(0.526-0.847, P=0.031)$; its sensitivity and specificity were $91.3 \%$ and $55.2 \%$, respectively.

\section{Discussion}

Gestational diabetes is very common and often has serious adverse consequences for the mothers and children. Similar to other reports, we also found that the GDM group had a higher weight and higher incidence of neonatal hypoglycemia than the healthy group [21, 22]. The BMI and total cholesterol level of GDM patients in the second and third trimesters were significantly higher 


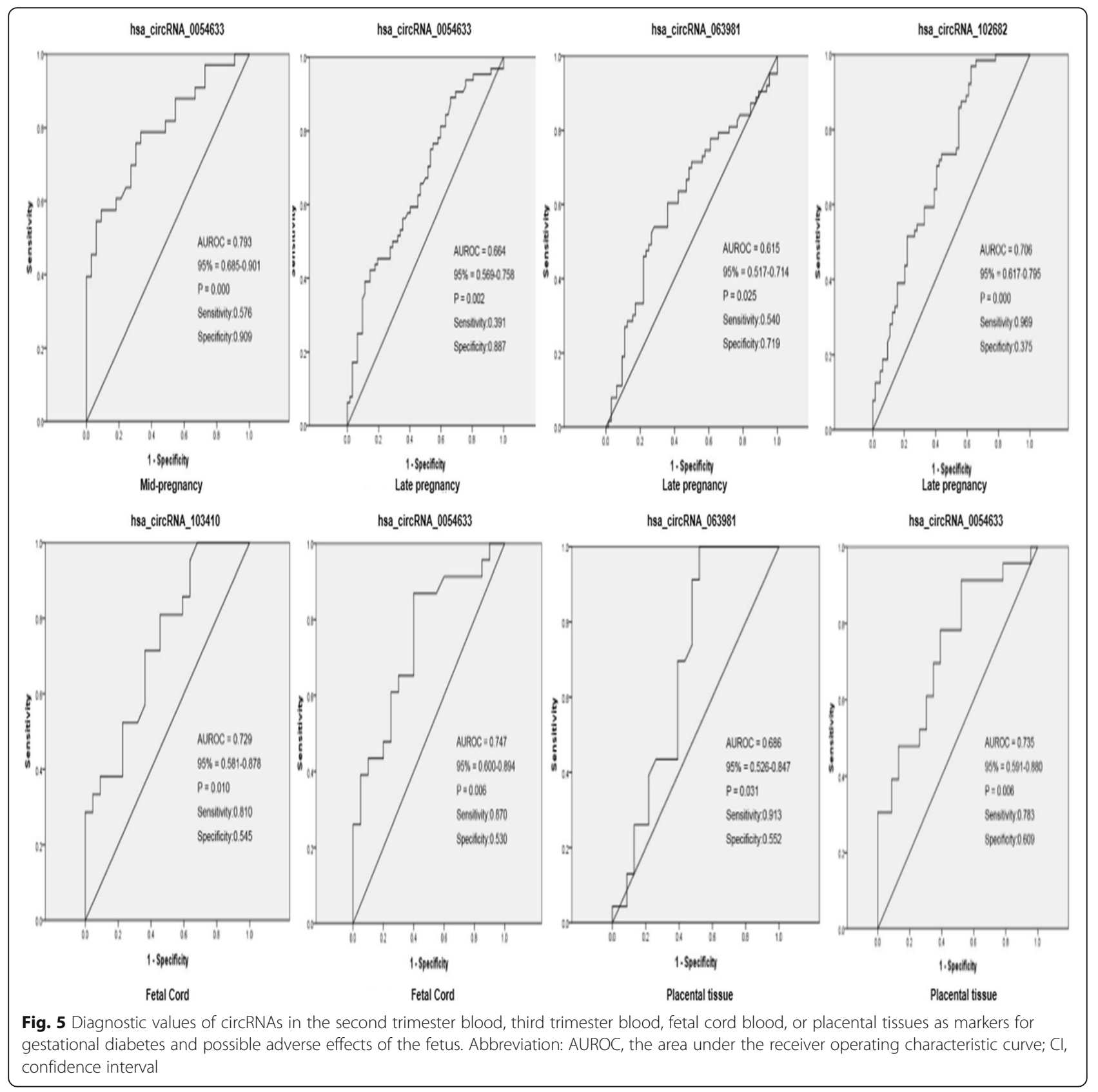

than that of the controls, while HDL was lower in the cases than in the controls. During pregnancy, lipid levels gradually increase with gestational age [23, 24], and pregnancy is considered to be a condition of hyperlipidemia [25]. The United States National Cholesterol Education Program [26] has reported that patients with GDM have hypercholesterolemia, and earlier studies have suggested that non-coding RNAs are involved in regulating lipid homeostasis [27]. We analyzed the relationship between the tested circRNAs and lipid metabolism and found no association. Smolarczyk et al. [25] found that there was a positive correlation between estrogen levels in pregnant women and total lipid levels. However, the underlying cause of elevated blood cholesterol levels in GDM has not been fully elucidated.

In recent years, more and more researchers have proposed that epigenetic players such as non-coding RNAs are involved in the regulation of glucose metabolism in GDM [11, 28, 29]. CircRNAs are much more stable than linear RNAs in the cells. In some tissues, their expression levels are 10 times higher than linear RNAs [30]. Therefore, circRNAs are potentially better biomarkers than linear RNAs. We selected six circRNAs as 
candidate biomarkers and tested them in GDM patients. We found that hsa_circRNA_0054633 had the highest diagnostic value in GDM. Hsa_circRNA_0054633 was highly expressed in the serum in the second and third trimesters and also in the placenta and was positively correlated with postprandial blood glucose, GHBA1, and GHABA1c $(P<0.05)$. Zhao et al. showed that hsa_circRNA_0054633 is involved in biological processes such as cell cycle progression and also closely related to molecular catabolism [31]. The proliferation of pancreatic $\beta$ cells is regulated by cell cycle progression, and a decrease in $\beta$ cell proliferation is the main cause of diabetes where insulin secretion is insufficient [32]. Therefore, our results suggest that hsa_circRNA_0054633 may be involved in the regulation of pancreatic $\beta$ cell proliferation and glucose metabolism during pregnancy. In addition, epigenetic changes in the placenta reflect the maternal diet and GDM metabolism [19]. We found that hsa_circRNA_0054633 is highly expressed in the placental tissues of the GDM group. Our finding suggests that hsa_circRNA_0054633 further affects the epigenetic changes in the placenta during its involvement in the regulation of glucose metabolism in maternal serum. However, placental factors can often lead to poor pregnancy outcomes which is associated with early placental development defects, and placenta inflammation, leading to increased risk of miscarriage, stillbirth, and fetal growth restriction [33]. Furthermore, we found that GDM cord blood has low levels of hsa_circRNA_0054633, suggesting that GDM can cause epigenetic changes in the cord blood, which might affect neonates. The specific mechanism needs to be further studied. By analyzing the area under the ROC curve in serum samples and placentas, we find that the diagnostic value of hsa circRNA_0054633 for GDM was the highest among all circRNAs tested. Compared with known biomarkers, such as plasma protein profiling in the second trimester and hair metabolomics, hsa_circRNA_0054633 is more stable and highly sensitive and may predict neonatal complications. Hsa_circRNA_0054633 may participate in the development of GDM by affecting cell metabolism and cell cycle in early pregnancy and may further affect neonates through epigenetic changes in the placenta and cord blood. However, the specific role of this circRNA in GDM requires further investigation. There was a strong correlation between hsa_circRNA_0054633 and hsa_circRNA_103410 in the third-trimester maternal blood and in the umbilical cord blood, while hsa_circRNA_103410 only showed significant differences in the placenta tissue between GDM patients and healthy subjects. The hsa circRNA_063981 level was low in the serum of GDM patients during the third trimester but high in the cord blood, and its expression in the placenta was correlated with hsa_circRNA_103410 expression $(P<0.05)$.
$\mathrm{Gu}$ et al. [34]. proposed in a study that has_circRNA_063981 and hsa_circRNA_103410 participate in and regulate diabetic retinopathy. Our results suggest that these three circRNAs interact with each other and may cause adverse outcomes by modulating glycometabolism. The specific mechanism needs to be further studied.

In conclusion, hsa_circRNA_0054633 is highly expressed in GDM at different stages of pregnancy and is closely related to glycosylation markers. This study determined that hsa_circRNA_0054633 is a potentially highly sensitive serum biomarker for GDM. This finding opens up possibilities for the diagnosis of GDM and treatment by regulating the expression of hsa_circRNA_0054633.

\section{Materials and methods \\ Subjects}

A retrospective case-control study was conducted at the Ningbo University Medical Center Li Huili Eastern Hospital, China. The time the patients were diagnosed with GDM was from July 10, 2017, to February 15 , 2018. Specimens included maternal serum samples, fetal cord blood, and placental tissue. Maternal serum samples were from the second trimester (2428 weeks) and third trimester (36-41 weeks). Fetal cord blood and placental tissues were extracted immediately after delivery. In this study, we excluded women who had other pregnancy-associated diseases, chronic hypertension, multiple pregnancies, gynecological diseases, liver or kidney disease, cancer, pre-pregnancy type 1 or type 2 diabetes, or obesity $(B M I \geq 30)$. Those who were smoking were also excluded. This study was approved by the Ethics Committee of the Medical College of Ningbo University. During the collection of specimens for this study, all participants provided informed consent to use their blood and tissue samples in research. Pregnant women were screened for GDM at 24 to 28 weeks of gestation. If the fasting plasma glucose (FPG) level was $5.1 \mathrm{mmol} / \mathrm{L}$ or higher, GDM was diagnosed. GDM was ruled out if the FPG level was $4.4 \mathrm{mmol} / \mathrm{L}$ or less. Women whose FPG level was greater than $4.4 \mathrm{mmol} / \mathrm{L}$ but less than $5.1 \mathrm{mmol} / \mathrm{L}$ underwent a 75-g oral glucose tolerance test (OGTT). In this case, GDM was diagnosed when 1 -h OGTT $\geq 10.0 \mathrm{mmol} / \mathrm{L}$ or 2 -h OGTT $\geq 8.5 \mathrm{mmol} / \mathrm{L}$. In this study, none of the subjects in the GDM group were given drugs or insulin injections to control blood glucose levels.

Specimens were collected from four cohorts: the second trimester (24-28 weeks) cohort included 40 GDM females (cases) and 40 healthy pregnant women (controls); the third trimester (36-41 weeks) cohort included 65 GDM patients and 65 healthy pregnant women; umbilical cord blood was from 20 GDM cases and 20 women without GDM; and placental tissues were from 
another 20 GDM cases and 20 women without GDM. Cases and controls were matched by age and BMI in all cohorts. Plasma hemoglobin levels were measured using a commercially available photometric method (SYSMEX, Hyôgo-ken, Japan). Blood biochemistry markers, including alanine aminotransferase (ALT), low-density lipoprotein (LDL), triglycerides, total cholesterol, and high-density lipoprotein (HDL), were assessed using a chemical analyzer (Siemens, Shanghai, China).

\section{Specimen collection and preservation}

Serum samples of pregnant women were collected from the Li Huili Eastern Hospital of Ningbo University Medical Center from July 10, 2017, to February 15, 2018. In the second trimester (24-28 weeks) and third trimester (36-41 weeks), peripheral venous blood $(3 \mathrm{~mL})$ was collected and then centrifuged (3000 rpm for $10 \mathrm{~min}$ at room temperature). The serum was then immediately collected and stored at $-80^{\circ} \mathrm{C}$ until use. Fetal umbilical cord blood ( $3 \mathrm{ml})$ was collected immediately after the child was born, and then, the serum was collected by centrifugation and stored at $-80^{\circ} \mathrm{C}$ until use. After the placenta was delivered, placental leaflets about $1 \times 1 \times 1 \mathrm{~cm}$ below the umbilical cord were quickly excised into sterile RNase-free 2.0-ml centrifuge tubes and flash frozen in liquid nitrogen. These specimens were then stored at $-80^{\circ} \mathrm{C}$ until use.

\section{Total RNA extraction and CDNA synthesis}

Total RNA was isolated from the serum and placental tissue using TRIzol LS Reagent (Invitrogen, Karlsruhe, Germany) and TRIzol Reagent (Invitrogen), respectively, according to the manufacturer's instructions. The purity of the extracted RNA was measured by a UV spectrophotometer using the following criteria: the $260 / 280 \mathrm{~nm}$ absorbance ratio of a qualified sample should be between 1.8 and 2.1. Among the extracted RNA samples, the number of sample failures in the second trimester and third trimester was kicked out by six and nine, respectively. RNA was reverse-transcribed into cDNA using HiFi-MMLV cDNA first strand synthesis kit (CWBIO) under the following conditions: $42^{\circ} \mathrm{C}$ for $50 \mathrm{~min}, 85^{\circ} \mathrm{C}$ for $5 \mathrm{~min}$, and immediately stored at $-80^{\circ} \mathrm{C}$ until use.

\section{Quantitative reverse transcription-polymerase chain reaction (qRT-PCR)}

For quantification, real-time PCR analysis was performed using the LightCycler 480 SYBR Green I Master kit on a LightCycler 480 II (Roche). qRT-PCR was performed under the following conditions: $95^{\circ} \mathrm{C}$ for a $5 \mathrm{~min}$ initial denaturation step, followed by 45 cycles of $94{ }^{\circ} \mathrm{C}$ for $10 \mathrm{~s}$, primer pair-specific annealing temperature for $20 \mathrm{~s}$, and $72{ }^{\circ} \mathrm{C}$ for $30 \mathrm{~s}$. Primers are listed in Additional file 1: Table S1. The annealing temperature for hsa_circRNA_0054633, hsa_circRNA_ 0018508 , and hsa_circRNA_103410 was $59^{\circ} \mathrm{C}$; for hsa_circRNA_063981 was $55^{\circ} \mathrm{C}$; for hsa_circRNA_102682 was $59^{\circ} \mathrm{C}$; and for $\beta$-actin and hsa_circRNA_104820 was $56^{\circ} \mathrm{C}[31,34,35]$. The relative fold changes were calculated by the comparative threshold cycle method, and $\beta$-actin was used as the internal normalization control. The experiment was performed independently three times.

\section{Statistical analyses}

Statistical analysis of the data was performed using GraphPad Prism 5.0 for Windows and SPSS software version 18.0. Variables with different distributions were expressed as means \pm standard deviations, medians (quartiles), or percentages. All data were first tested using the Kolmogorov-Smirnov test to see if the variables were normally distributed. When the variables satisfied the normal distribution, homogeneity tests for variance were performed. Independent samples $t$ tests were used when normal distribution and homogeneity of variance were both satisfied. If one of the conditions was not met, the Mann-Whitney $U$ test was used. When comparing the frequency of categorical variables, we used the Pearson's $\chi^{2}$ test. $P<0.05$ was considered statistically significant. The correlation between two variables was analyzed using the Pearson correlation test. The expression level of a gene was represented by the following formula: $\Delta C_{\mathrm{T}}=C_{\mathrm{T}}$ (target gene) $-\Delta C_{\mathrm{T}}$ (internal reference gene), $\Delta \Delta C_{\mathrm{T}}=\Delta C_{\mathrm{T}}$ (case group gene of interest) $-\Delta C_{\mathrm{T}}$ (control group gene of interest). When $\Delta \Delta C_{\mathrm{T}}<0$, the expression of the target gene was upregulated in the case group, and the expression was downregulated when $\Delta \Delta C_{\mathrm{T}}>0$. To determine the diagnostic value of circRNA for gestational diabetes in the four study cohorts, we established a ROC curve for each study cohort. The AUC was calculated for each circRNA.

\section{Additional file}

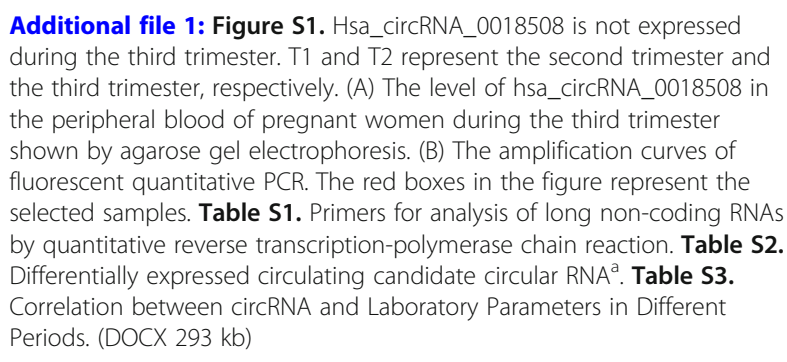

\section{Abbreviations}

ALT: Glutamic pyruvic transaminase; APOA1: Apolipoprotein A1; APOB: Apolipoprotein B; APOE: Apolipoprotein E; AST: Glutamic oxaloacetic transaminase; BMI: Body mass index; CircRNA: Circular RNA; HDL-C: High- 
density lipoprotein cholesterol; LDL-C: Low-density lipoprotein cholesterol; OGTT: Oral glucose tolerance test; TBA: Total bile acid

\author{
Acknowledgements \\ The authors acknowledge the contribution of the University of Ningbo \\ University Diabetes Center Laboratory.
}

\section{Funding}

This work was supported by Ningbo Science and Technology Innovation Team Program (2014B82002), Ningbo 3315 Program (2013A-10-G), Specia Funding in Ningbo Medical Center Lihuili Eastern Hospital (2017DYKY02), Fang Runhua Fund of Hong Kong, and K. C. Wong Magna Fund in Ningbo University.

\section{Authors' contributions}

All authors were responsible for the study conception, design, and funding YZ and SB supervised the study. HW obtained the data. YZ, HW, and SB performed data analysis and interpretation. SB and $Y Z$ provided clinical expertise for the analysis. HW and SW drafted the manuscript, and $Y Z, S W$, YZ, MY, and SB made critical revisions for intellectual content. All authors approved the final version of the manuscript and agreed to be accountable for all aspects of the work.

\section{Ethics approval and consent to participate}

The present study was approved by the Ethics Committee of the Medical School of Ningbo University. All participants provided informed consent for the use of their blood samples in clinical studies.

\section{Consent for publication}

Not applicable.

\section{Competing interests}

The authors declare that they have no competing interests.

\section{Publisher's Note}

Springer Nature remains neutral with regard to jurisdictional claims in published maps and institutional affiliations.

Received: 19 July 2018 Accepted: 4 January 2019

Published online: 08 February 2019

\section{References}

1. Metzger BE, Coustan DR. Summary and recommendations of the fourth international workshop-conference on gestational diabetes mellitus. The Organizing Committee. Diabetes Care. 1998;21(Suppl 2):B161-7.

2. Zhu Y, Zhang C. Prevalence of gestational diabetes and risk of progression to type 2 diabetes: a global perspective. Curr Diab Rep. 2016;16:7.

3. Yuen L, Wong WW. Gestational diabetes mellitus: challenges for different ethnic groups. World J Diabetes. 2015;6:1024-32.

4. 2. Classification and Diagnosis of Diabetes. Diabetes Care. 2016;39(Suppl 1):S13-22

5. Cho NH, Whiting DR, Guariguata L. International Diabetes Federation (IDF). In: IDF Diabetes Atlas. 6th ed; 2013.

6. Burlina S, Dalfra MG, Chilelli NC, Lapolla A. Gestational diabetes mellitus and future cardiovascular risk: an update. Int J Endocrinol. 2016;2016:2070926.

7. Agarwal MM. Gestational diabetes mellitus: an update on the current international diagnostic criteria. World J Diabetes. 2015;6:782-91.

8. Zhao C, Wang F, Wang P, Ding H, Huang $X$, Shi Z. Early second-trimester plasma protein profiling using multiplexed isobaric tandem mass tag (TMT) labeling predicts gestational diabetes mellitus. Acta Diabetol. 2015;52:1103-12.

9. He X, de Seymour JV, Sulek K, Qi H, Zhang H, Han TL, Villas-Boas SG, Baker PN. Maternal hair metabolome analysis identifies a potential marker of lipid peroxidation in gestational diabetes mellitus. Acta Diabetol. 2016;53:119-22.

10. Bhavadharini B, Mahalakshmi MM, Maheswari K, Kalaiyarasi G, Anjana RM, Deepa M, Ranjani H, Priya M, Uma R, Usha S, et al. Use of capillary blood glucose for screening for gestational diabetes mellitus in resourceconstrained settings. Acta Diabetol. 2016:53:91-7.

11. Zhang $Y$, Wu H, Wang F, Ye M, Zhu H, Bu S. Long non-coding RNA MALAT1 expression in patients with gestational diabetes mellitus. Int J Gynaecol Obstet. 2018;140:164-9.
12. Chidambaram M, Liju S, Saboo B, Sathyavani K, Viswanathan V, Pankratz N, Gross M, Mohan V, Radha V. Replication of genome-wide association signals in Asian Indians with early-onset type 2 diabetes. Acta Diabetol. 2016;53:915-23.

13. Barrett SP, Wang PL, Salzman J. Circular RNA biogenesis can proceed through an exon-containing lariat precursor. eLife. 2015;4:e07540.

14. Lukiw WJ, Circular RNA. (circRNA) in Alzheimer's disease (AD). Front Genet. 2013;4:307.

15. Qin M, Liu G, Huo X, Tao X, Sun X, Ge Z, Yang J, Fan J, Liu L, Qin W. Hsa_ circ_0001649: a circular RNA and potential novel biomarker for hepatocellular carcinoma. Cancer biomarkers: section A of disease markers. 2016;16:161-9.

16. Li F, Zhang L, Li W, Deng J, Zheng J, An M, Lu J, Zhou Y. Circular RNA ITCH has inhibitory effect on ESCC by suppressing the Wnt/beta-catenin pathway. Oncotarget. 2015;6:6001-13.

17. Burd CE, Jeck WR, Liu Y, Sanoff HK, Wang Z, Sharpless NE. Expression of linear and novel circular forms of an INK4/ARF-associated non-coding RNA correlates with atherosclerosis risk. PLoS Genet. 2010:6:e1001233.

18. Xu H, Guo S, Li W, Yu P. The circular RNA Cdr1as, via miR-7 and its targets, regulates insulin transcription and secretion in islet cells. Sci Rep. 2015;5:12453.

19. Brett KE, Ferraro ZM, Yockell-Lelievre J, Gruslin A, Adamo KB. Maternal-fetal nutrient transport in pregnancy pathologies: the role of the placenta. Int J Mol Sci. 2014;15:16153-85.

20. Daskalakis G, Marinopoulos S, Krielesi V, Papapanagiotou A, Papantoniou N, Mesogitis S, Antsaklis A. Placental pathology in women with gestational diabetes. Acta Obstet Gynecol Scand. 2008;87:403-7.

21. Dabelea D, Hanson RL, Lindsay RS, Pettitt DJ, Imperatore G, Gabir MM, Roumain J, Bennett PH, Knowler WC. Intrauterine exposure to diabetes conveys risks for type 2 diabetes and obesity: a study of discordant sibships. Diabetes. 2000;49:2208-11.

22. Krstevska B, Jovanovska SM, Krstevska SS, Nakova W, Serafimoski V. Maternal lipids may predict fetal growth in type 2 diabetes mellitus and gestational diabetes mellitus pregnancies. Prilozi (Makedonska akademija na naukite i umetnostite Oddelenie za medicinski nauki). 2016:37:99-105.

23. Knopp RH, Magee MS, Walden CE, Bonet B, Benedetti TJ. Prediction of infant birth weight by GDM screening tests. Importance of plasma triglyceride. Diabetes Care. 1992;15:1605-13.

24. Barrett HL, Dekker Nitert M, McIntyre HD, Callaway LK. Normalizing metabolism in diabetic pregnancy: is it time to target lipids? Diabetes Care. 2014:37:1484-93.

25. Smolarczyk R, Czajkowski K, Wojcicka-Jagodzinska J, Kostro I, Demkow K, Teliga-Czajkowska J, Mrozek J. The influence of chosen hormones on lipids and its correlation during normal pregnancy. Ginekol Pol. 2001;72: 765-71.

26. Third Report of the National Cholesterol Education Program (NCEP) expert panel on detection, evaluation, and treatment of high blood cholesterol in adults (adult treatment panel III) final report. Circulation. 2002;106:3143-421.

27. Sallam T, Jones MC, Gilliland T, Zhang L, Wu X, Eskin A, Sandhu J, Casero D, Vallim TQ, Hong C, et al. Feedback modulation of cholesterol metabolism by the lipid-responsive non-coding RNA LeXis. Nature. 2016:534:124-8.

28. Cao YL, Jia YJ, Xing BH, Shi DD, Dong XJ. Plasma microRNA-16-5p, -17-5p and -20a-5p: novel diagnostic biomarkers for gestational diabetes mellitus. J Obstet Gynaecol Res. 2017;43:974-81.

29. Sebastiani G, Guarino E, Grieco GE, Formichi C, Delli Poggi C, Ceccarelli E, Dotta F. Circulating microRNA (miRNA) expression profiling in plasma of patients with gestational diabetes mellitus reveals upregulation of miRNA miR-330-3p. Front Endocrinol. 2017;8:345.

30. Jeck WR, Sorrentino JA, Wang K, Slevin MK, Burd CE, Liu J, Marzluff WF, Sharpless NE. Circular RNAs are abundant, conserved, and associated with ALU repeats. RNA. 2013;19:141-57.

31. Zhao Z, Li X, Jian D, Hao P, Rao L, Li M. Hsa_circ_0054633 in peripheral blood can be used as a diagnostic biomarker of pre-diabetes and type 2 diabetes mellitus. Acta Diabetol. 2017:54:237-45.

32. Rane SG, Reddy EP. Cell cycle control of pancreatic beta cell proliferation. Front Biosci. 2000:5:D1-19.

33. Ilekis JV, Tsilou E, Fisher S, Abrahams VM, Soares MJ, Cross JC, Zamudio S, Illsley NP, Myatt $L$, Colvis $C$, et al. Placental origins of adverse pregnancy outcomes: potential molecular targets: an Executive Workshop Summary of the Eunice Kennedy Shriver National Institute of Child Health and Human Development. Am J Obstet Gynecol. 2016;215:S1-S46. 
34. Gu Y, Ke G, Wang L, Zhou E, Zhu K, Wei Y. Altered expression profile of circular RNAs in the serum of patients with diabetic retinopathy revealed by microarray. Ophthalmic Res. 2017;58:176-84.

35. Qian Y, Lu Y, Rui C, Qian Y, Cai M, Jia R. Potential significance of circular RNA in human placental tissue for patients with preeclampsia. Cell Physiol Biochem. 2016:39:1380-90.

Ready to submit your research? Choose BMC and benefit from:

- fast, convenient online submission

- thorough peer review by experienced researchers in your field

- rapid publication on acceptance

- support for research data, including large and complex data types

- gold Open Access which fosters wider collaboration and increased citations

- maximum visibility for your research: over $100 \mathrm{M}$ website views per year

At $B M C$, research is always in progress.

Learn more biomedcentral.com/submissions 